\title{
La Voluntaria InCOHERENCIA
}

The Voluntary Incoherence

Aldo Vivar Mendoza ${ }^{1}$

¿CuÁl es el espesor de la frontera entre la MEDICINA Y EL ARTE?

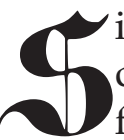
iendo un estudiante, Claude Bernard compuso una obra dramática que no fue del agrado de su profesor de teatro, quilen le recomendó que mejor se dedicara a la medicina. Este profesor nos hizo un favor pues nos legó a uno de los mejores fisiólogos de la historia.

Anton Chekhov atendía a sus pacientes durante el día para consumirse escribiendo durante la noche, y lo único que se recuerda de su actividad médica fue la tuberculosis que terminó matándolo prematuramente en un hospicio de Badenweiler pero su estela literaria alumbra hasta hoy el estilo de numerosos cuentistas en todo el mundo.

Como Bernard y Chekhov, André Breton transitó durante años entre el espesor de aquella frontera entre la medicina y el arte.

Breton nació en el norte de Francia en 1896, su padre fue gendarme y ateo, su madre costurera y de un catolicismo militante. André inició sus años escolares en un colegio católico

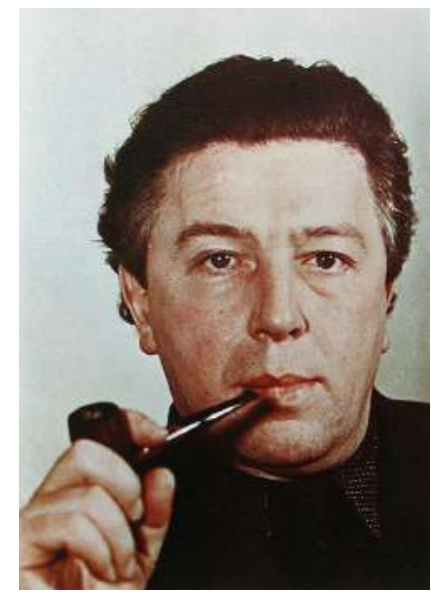

André Breton, París, 1939

(Reproducido de http: / / www.gisele-freund.com/writers /)

para luego recalar en uno laico, allí destacó por tener buenas calificaciones y hasta recibir diplomas.

Hacia octubre de 1907 la familia se mudó a París y el joven André fue matriculado en el liceo Chaptal, su rendimiento escolar fue más que satisfactorio tanto en humanidades como en ciencias, salvo algunas anotaciones en el rubro de conducta (por hablar demasiado en

1 Médico internista. Facultad de Medicina, Universidad Peruana Cayetano Heredia. 
clase). André, quien años más tarde confesaría una incapacidad para aprender idiomas, no estudió las obligatorias lenguas clásicas sino que optó por el alemán, gracias a una ley de la época. En aquel idioma obtuvo buenas calificaciones, lo que le permitió ser enviado por sus padres a una estancia estival en 1910 a la región de la Selva Negra alemana donde su manejo del idioma mejoró notablemente y le permitió tener acceso directo a la literatura y filosofía alemanas, sobre todo de los escritores del romanticismo.

A su regreso del viaje, André, ya adolescente, ingresó al último año del liceo mostrando cierta inconformidad con la rigidez y disciplina de la educación que se impartía en Chaptal. En ese año conoció a un compañero de estudios recientemente transferido a su salón de clase, Theodore Fraenkel, hijo de emigrantes ruso judíos con quien hizo una amistad de por vida. Ambos compartían un interés común: la poesía.

Albert Keim, un profesor de Chaptal, impresionado por el valor literario de una composición del joven André, lo invitó a su círculo de tertulias literarias y en su biblioteca André conocería la obra de Mallarmé, Baudeleire. Esta invitación le permitió además descubrir a un grupo de jóvenes que como él compartían su interés en la poesía. Tales amistades le abrieron la puerta a la publicación en revistas literarias. Sin embargo, las notas de André no eran del todo satisfactorias en gran parte por la antipatía que le tenía a su profesor principal, un rígido conservador y seguidor de la filosofía de Kant. Con las mediocres calificaciones obtenidas, André no era apto para ingresar al Politécnico como querían sus padres. Así que, por "proceso de eliminación", escogió la carrera de medicina como mal menor, pues pensaba que de este modo tendría más libertad para ejercer "otras actividades intelectuales" como escribir poemas. Como era de esperarse en esta aventura lo acompañó su amigo Theodore, quien al parecer sí tenía mayores convicciones para el estudio de la medicina. Para tal fin, en octubre de 1913 André y Theodore empezaron el curso de Física, Química y Ciencias Naturales (PCN, por sus siglas en francés) que era el preparatorio para la carrera de medicina. Sin embargo, para André el entusiasmo por las tertulias poéticas era mayor que la asistencia a los salones de clase o los gabinetes de laboratorio. Para complicar un poco más las cosas, a inicios de 1914 ocurrió algo que inclinó la vocación al lado literario, la revista neosimbolista La Phalange publicó tres poemas de André, cuya composición estaba claramente influida por el oscuro estilo de Mallarmé. Con todo ello, André no logró aprobar el examen de admisión a la escuela de medicina, lo que sí logró Theodore. Pero en un segundo intento, André obtuvo las calificaciones necesarias.

Mientras tanto, el fantasma de la guerra volvía a asolar a Europa, en julio de 1914 el Imperio Austro Húngaro le declaró la guerra a Serbia y como en un juego de dominó se acoplaron rápidamente otros países hasta formar dos bandos, la Triple Alianza (Alemania, Imperio Austro Húngaro e Italia) contra la Triple Entente (Rusia, Inglaterra y Francia). La movilización de tropas fue casi inmediata pues desde la guerra de 1870 todos los países europeos habían desarrollado una imparable carrera armamentista.

En 1915, a sus 19 años, André fue llamado a la movilización. Pasó todas las evaluaciones físicas que lo declararon apto para el servicio y, en vista que sus estudios médicos aun no eran suficientes, fue destacado como enfermero militar. Para entonces, André alternaba la escuela de medicina con una intensa actividad cultural, participando en los círculos literarios 
donde descubrió la poesía iconoclasta de Rimbaud, lo que cambiaría radicalmente su forma de ver al mundo y a su poesía. Es en esta bohemia que conoció, además, la obra de Guillaume Apollinaire.

Apollinaire, hijo de una inmigrante polaca y un aristócrata italiano, nació en Roma en 1880. A los 20 años decidió establecerse en París, donde rápidamente se convirtió en animador de la bohemia parisina, sus contactos con Picasso, Matisse, Duchamp, De Chirico, entre otros, lo convirtieron en un icono del vanguardismo. En 1914, publicó el poemario Alcools y al año siguiente en un artículo suyo publicado en la revista Les Soirées de París comentó que la principal fuerza estética moderna era la sorpresa. Este principio con el correr del tiempo se convirtió en la característica principal del modernismo que se extendió desde la pintura a la literatura y desde allí a todo el arte de la vanguardia. En ese mismo año, Apollinaire publicó el artículo Surnaturalisme también en Les Soirées de París donde declaró su arte poética en favor de "un supernaturalismo, más sensible, más vital y más variado [que represente la realidad], un surnaturalismo enteramente en concordancia con lo expresado en otras artes... Nada es bello, excepto la Verdad". Tres años después el mismo Apollinaire cambió surnaturalismo por surrealismo pero manteniendo la esencia del concepto, un realismo que va más allá de su apariencia externa para concentrarse en la naturaleza interior de las cosas.

Para congraciarse con su país de adopción, Apollinaire se enlistó en el ejército francés en 1915 y fue enviado el frente en la sección de artillería como teniente segundo. Desde la línea de combate siguió escribiendo poemas. Cierto día, en una trinchera reventó una granada mientras Apollinaire leía. Una esquirla atravesó el casco. La cabeza comenzó a sangrar. Tuvo que ser evacuado y sometido a craneotomía.
Retirado de combate, Apollinaire, luego de un largo y penoso proceso de convalecencia, regresó a la bohemia parisina.

Tiempo más tarde, André tomó el valor necesario para remitir un poema a Apollinaire quien le escribió luego una nota diciendo "sus versos muestran un gran talento". Guillaume y André se encontrarían luego en variadas tertulias de la bohemia parisina, donde André conocería a Philippe Soupault, hijo de un gastroenterólogo y aspirante a poeta, quien a causa de una reacción adversa a una vacuna para la tifoidea se había librado del enrolamiento. Philippe estudiaba leyes por decisión paterna aunque su vocación fuera la botánica y su afición la literatura.

Apollinaire publicó “Les Mamelles des Tirésias", su primera "obra surrealista", en cuyo prólogo anotó "es necesario volver a la realidad en símisma pero sin retratarla fotográficamente. Cuando el hombre quiso imitar la caminata inventó la rueda -que no se parece a una pierna-. De esta manera cometió un actosurrealista sin saberlo." Apollinaire se casó y también se pasó al lado oficialista, sus escritos originalmente vanguardistas contra la guerra se convirtieron en pro bélicos, trayendo abajo la ilusión de jóvenes como Breton. Apollinaire sobrevivió a las trincheras pero sucumbió ante la epidemia de influenza que asoló Europa al mismo tiempo que la guerra. Murió solo dos días antes de que se declarara el armisticio.

\section{Pero Guillaume \\ APOLLINAIRE \\ acaba de \\ morir}

(André Bretón, en el final de una carta a uno de sus amigos.)

André Bretón tuvo un bautizo de su vocación en los cuarteles donde años después conocería, 
según sus palabras, "la sangre, el fango y la imbecilidad."

Mientras tanto, la guerra había apagado París. Los racionamientos y los apagones se habían convertido en rutina. Los cines y las librerías permanecían cerrados, solo la actividad literaria, acaso una forma de conspiración, animaba a los jóvenes quienes se repartían los poemas por correspondencia.

En 1916, André fue trasladado a Nantes donde se dedicó a practicar la medicina para luego volver a ser trasladado al centro neuropsiquiátrico de Saint Dizier bajo la tutela del doctor Raoul Achilles Leroy, en cuya biblioteca tuvo acceso a las obras de Jean Martin Charcot (el padre de la neurología francesa), Emil Kraepelin (un influyente psiquiatra alemán), Constanza Pascal (quien había escrito un tratado sobre la dementia praecox -esquizofrenia-, Valentin Magnan (y su teoría de la degeneración mental), Emmanuel Régis (Précis de psychiatrie y La psychoanalyse des neuroses et des psychoses), escrito con Angelo Hesnard, obras que le abrirían el conocimiento de las teorías de Sigmund Freud. Breton era un buen alumno y destacaba por la acuciosidad en los diagnósticos; así, cierta vez identificó correctamente un caso de tabes dorsalis, una complicación neurológica de la sífilis, que había sido obviado por otros médicos.

Además de practicar neurología en Saint Dizier, esta rotación fue para Breton un momento capital en su vida pues estuvo en la capacidad de tomar decisiones acerca del diagnóstico de enfermedad mental de ciertas personas con sospechas de insania, como era llamada la locura. En aquel hospital fue capaz de experimentar con los métodos de la libre asociación, la interpretación de los sueños y el psicoanálisis, aplicando una vez más las enseñanzas de sus lecturas en los turbulentos años de la guerra.

En una nota a su amigo Fraenkel, André escribiría:

Dementia praecox, paranoia, estados crepusculares

¡Oh la poesía alemana, Freud y Kraepelin

El centro psiquiátrico admitía soldados que habían pasado por las trincheras, el silbido de las balas, el estruendo de las granadas, la fiebre el tifus y sobrevivido al gas mostaza. Aquellos hombres eran evacuados del frente a causa del estallido de crisis nerviosas que revivían el horror y el miedo. André escuchaba maravillado las historias que recogía de aquellos pacientes jóvenes, llegando a considerar, por sus diálogos, que algunos de ellos le parecían mejores poetas que él.

Aquella liberación de la mente era para André un sustrato para la creación poética, así se lo hizo saber a quienes consideraba sus mentores, como Apollinaire y Valéry, así como a Vaché, uno de sus amigos, quien le pidió de ser posible establecer correspondencia con una paranoide o un catatónico para discutir sobre poesía.

A sugerencia de Leroy, quien le aconsejó presentar reportes de caso, André escribió algo más parecido a una narración en prosa que a un caso para médicos. Hasta tenía título: "Tema". Allí se describía a un soldado "capaz de señalar con su dedo la trayectoria de las granadas" y que se consideraba a si mismo inmune a las balas aduciendo que la guerra no existía. El relato terminó publicado en la revista Nord Sud y era un híbrido narrativo, frío y detallista como un reporte clínico escrito con una prosa exquisita. 
Ante las numerosas bajas de los médicos, el gobierno francés dispuso que los estudiantes de medicina fueran destinados al campo de batalla, en Saint Dizier, contra la opinión de Leroy, el soldado André Breton fue asignado como camillero pero ante la escasez de personal muchas veces ejerció de médico. Su destino: Verdún, a orillas del río Mosa. Esta batalla fue la más sangrienta y encarnizada de la Gran Guerra, que se extendió de febrero a noviembre de 1916. Se lanzaron millones de obuses, murieron 300000 hombres de ambos bandos. Los soldados franceses que sobrevivían a las bombas y balas tenían que enfrentarse al lanzallamas y al gas. André solo estuvo cuatro meses, los suficientes para sentir de cerca la carnicería de las trincheras y el olor a cuerpos chamuscados y putrefactos. A causa de la intensidad de las acciones bélicas solo podían recoger a los heridos durante la noche. Entre la sangre, las vísceras desperdigadas en el suelo y el pánico de los heridos, André, como cualquier soldado, se las arreglaba para enviar cartas, y poemas, desde el frente.

Al término de su asignación, André fue trasladado a París, allí decidiría continuar sus estudios médicos. André estaba fascinado por la neuropsiquiatría y deseaba explorar las herramientas del psicoanálisis. Las experiencias de la guerra cambiaron la manera de pensar de Breton, así como sucedía sobre sus ideas poéticas que se fueron nutriendo sucesivamente de Mallarmé, Baudelaire, Rimbaud y Apollinaire. André vivía una dualidad vocacional, le interesaba tanto la medicina como la poesía y aun no pensaba renunciar a ninguna de ellas.

¿Hasta dónde llegan los confines de la locura?

Animado por sus lecturas en neurología, André solicitó una plaza en el Hospital La Pitié como estudiante no residente bajo la tutoría de Joseph Babinski, rotación que hizo de enero a setiembre de 1917.

Babinski, entonces ya era famoso, había sido uno de los alumnos predilectos de Charcot en La Salpetriere, así su relación académica había sido registrada en la pintura de Brouillet. El signo clínico que lo inmortalizó fue el reflejo plantar que se presenta al pasar un estilete por el borde externo del pie y consiste en la extensión del dedo gordo del pie examinado cuando existe cierto daño cerebral, como un tumor o una afección vascular, de tal modo que se diferencian los pacientes con enfermedad cerebral de aquellos casos simuladores como la histeria. Babinski era la estrella académica de la neurología francesa permaneciendo en La Pitié hasta su retiro en 1922. El profesor le regaló a André un ejemplar de su libro "Hysteria-Pithiatisme", con una dedicatoria y sus augurios de una carrera médica exitosa.

Los sucesos posteriores, a pesar de que André no continuaría con la medicina, mostrarían la huella indeleble que ejerció Babinski en el poeta. La neurología se estaba convirtiendo en una medicina de hechos, de signos clínicos, más que la psiquiatría que lidiaba con las emociones, el comportamiento y el lenguaje como expresiones del subconsciente.

Al terminar su rotación en La Pitié, André fue destacado contra su voluntad al hospital militar Val de Grace. Allí conocería a otro estudiante con inclinaciones poéticas, Louis Aragon. Entre las vicisitudes de la vida en un hospital y la atención de pacientes con alguna forma de locura o mutilaciones por la guerra, André haría un nuevo descubrimiento literario: "Los cantos de Maldoror", los poemas de Isidore Ducasse, cuyo pseudónimo era el Conde de Lautréamont, un poeta que murió de tuberculosis a los 24 años. 
"Ruego al cielo que el lector, animado y momentáneamente tan feroz como lo que lee, encuentre, sin desorientarse, su camino abrupto y salvaje, a través de las desoladas ciénagas de estas páginas sombrías y llenas de veneno...". Canto I.

Un ejemplar del libro, que fue conseguido por Philippe Soupault, era leído ávidamente por André y Louis quienes se refugiaban en el pabellón de insanos de Val de Grace, al que llamaban quatriéme fievreux (pabellón cuatro de las fiebres), y durante la madrugada leer en voz alta las páginas envenenadas del libro de Lautréamont, cuya narrativa gótica y cruel describía al demonio y a seres sobrenaturales en situaciones tanto fantásticas y desquiciadas como esquizofrénicas. La vociferación de los poemas alteraba la tranquilidad de los pacientes encerrados en sus celdas quienes se agitaban y al grito de ¡Auxilio, están locos! pretendían callar las declamaciones de aquellos estudiantes de medicina que aspiraban a poetas en medio de un París amenazado por una guerra que destruía cualquier esperanza.

"Esos gritos se oyen algunas veces en el silencio de las noches sin estrellas. Aunque los oigamos, sin embargo, el que lanza esos gritos no está cerca, pues esos lamentos pueden oirse a tres leguas de distancia, transportados por el viento de una ciudad a otra...". Canto I.

Sin embargo, ellos estaban allí, de guardia en el hospital

Poco tiempo después André descubrió Poésies de Lautréamont en los archivos de la Bibliothéque Nationale. Estos poemas diferían radicalmente de la prosa desquiciada de los Cantos, eran un elogio a la razón fría. La poesía de André ya no sería igual, dejaría el verso alejandrino por una composición libre que incluso incorporaba textos de otros poemas, una especie de collage narrativo.
Esto seguramente distrajo su atención, en los meses siguientes, pues meses después Louis Aragon aprobó el examen para auxiliar médico mientras que André lo reprobó. Un par de semanas después, André fue destacado a un regimiento de artillería, en Moret-sur-Lung, a 90 kilómetros de París, donde su vida fue algo apacible y le permitió hacer un examen de conciencia sobre sus influencias poéticas.

La guerra terminó en noviembre de 1918. André se reencontró con sus amigos Louis y Phillippe en la ideas de emprender nuevas aventuras literarias en tiempos de paz. Esperaba reunirse con Vaché, un amigo extravagante y nihilista y una poderosa influencia personal. El intercambio epistolar entre ambos era continuo. Sin embargo, pocos días después los diarios informaron de cuatro jóvenes muertos en un cuarto de hotel, intoxicados de opio, uno de ellos era Vaché. Este hecho provocó una conmoción moral en André que lo llevó a cuestionar los alcances y valores de lo que venía haciendo. Es en ese momento de su vida que descubrió un movimiento cultural creado en territorio neutral, más específicamente en el Cabinet Voltaire, un café en Zurich. Un grupo de intelectuales y artistas que habían escapado de la guerra negaba las formas de arte existentes, apostando por lo ilógico e irreverente. Tomaron su nombre al apuntar al azar una página del diccionario, la palabra escogida era simple y pegajosa: Dadá.

"... No tenemos miedo. No somos sentimentales. Somos como un viento furioso que desgarra el vestido de las nubes y las plegarias; estamos preparando el gran espectáculo del desastre, la conflagración y la destrucción...". Manifiesto Dadá (1918).

Destruir el orden previo para dar luz a otro. El brote cultural se había extendido rápidamente en New York, París y Barcelona e involucraba a artistas de diversas disciplinas, 
Marcel Duchamp, Man Ray, Max Ernst, Francis Picabia, entre otros. Esto impresionó muchísimo a André quien pronto estableció contacto con su líder y promotor, Tristan Tzara. Este movimiento rápidamente se apoderó rápidamente de la escena parisina.

Mientras tanto, André, Philippe y Louis fundaron una revista que luego de varios escarceos se llamó Littérature, publicación de poesía y prosa. Era el invierno de 1919, su primer número fue tibio y complaciente. André y sus secuaces decidieron romper los esquemas publicando un inédito de Rimbaud, producto de una intensa negociación y 500 francos.

Tzara llegó a París. Se organizaron muestras y performances teatrales que terminaban en escándalo. No era sencillo ser innovador y destructivo en el París de entonces. Las noticias de los disturbios llegaron a los diarios, incluso a los padres de André.

Louis y Marguerite Breton aparecieron de sorpresa en la habitación del Hotel des Grands Hommes donde se alojaba André, un 21 de marzo de 1920. El ultimátum de la madre fue claro: regresar a Lorient y reanudar sus estudios de medicina, de negarse le quitarían la pensión paterna.

André renunció a la medicina y se quedó con Dadá y Littérature. Nadie lo pudo convencer de lo contrario.

Gracias a la gestión de Paul Valéry, André consiguió trabajo en la editorial de Gastón Gallimard con un sueldo de 400 francos mensuales, que consistía en encargarse de la correspondencia, tareas administrativas y la distribución de la Nouvelle Revue Francaise (NRF), la competencia de Littérature. No era algo fácil de digerir pero André necesitaba el dinero y aceptó. Asimismo, recibiría 50 francos por sesión para ayudar a Marcel Proust en la corrección de las pruebas de "El mundo de Guermantes". La ayuda era leer en voz alta las galeras para que el autor tomara nota de los errores. Siendo conocido que Marcel había invertido su ritmo circadiano, André llegaba al número 44 de la rue Hamelin a las 11 de la noche para retirarse al amanecer.

Paralelamente, André y Philippe se embarcaron en una escritura conjunta de ideas espontaneas e inconexas, hecha de los que llamaban automatismos psíquicos, una deuda de las lecturas de las teorías de Pierre Janet. El libro se llamó Les champs magnétiques

Mientras tanto, el fuego destructor de Dadá se fue apagando, el movimiento entraba en contradicciones. El mismo André cuestionaba su apoyo, no bastaba con evocar al desorden por sí mismo, en un artículo publicado en la NRF escribió que la subversión debía dar lugar a obras e ideas, que la negación debía llevar a una revisión de los valores.

En el verano de 1920, André conoció a Simone Kahn, joven de clase media alta, la luz que iluminaría el "abismo negro" que era la vida de André, como él se describía a sí mismo. Se casaron el 15 de setiembre de 1921. Los recién casados partieron de luna de miel en un viaje por Europa, una de las paradas fue Viena.

El interés de visitar Viena era una entrevista con Sigmund Freud, la teoría del subconsciente y la interpretación de los sueños habían dejado una huella indeleble en el joven estudiante de medicina. Previamente, André le había enviado un ejemplar de Les champs magnétiques con una dedicatoria. La cita fue pactada para el 10 de octubre. Ese día André se presentó puntualmente en el consultorio de la calle Berggasse 19. La conversación fue fría y distante. Freud vio en André un poeta y no un 
médico en ciernes. El conocimiento superficial del psicoanálisis de André no le interesó a Freud quien, además, de literatura solo conocía a los clásicos y no sabía nada de la vanguardia. André habló de Charcot y Babinski como para animar a Freud, sin éxito. La entrevista terminó pronto para dar paso al paciente en espera. André salió muy desilusionado, tiempo después haría una crónica amarga de su encuentro con Freud.

De vuelta en París, André y sus amigos decidieron reflotar Littérature. Escribían textos automáticos, hicieron sesiones de hipnotismo, tuvieron desencuentros y peleas, sentían que andaban en círculos para paliar el aburrimiento decidieron dar un nuevo impulso.

André preparaba un nuevo libro al que denominó El pez soluble, conjunto de textos automáticos que hablaban sobre seres sobrenaturales. André imaginó un prefacio que los explicara. El prefacio, escrito esta vez con pulcritud y razonamiento, le salió de casi 70 páginas al que dio como título Manifiesto del Surrealismo.

SURREALISMO: s.m. Automatismo psíquico puro por cuyo medio se intenta expresar tanto verbalmente como por escrito o de cualquier otro modo el funcionamiento real del pensamiento. Dictado del pensamiento, con exclusión de todo control ejercido por la razón y al margen de cualquier preocupación estética o moral.

ENCICLOPEDIA: Filos. El surrealismo se basa en la creencia en la realidad superior de ciertas formas de asociación que habían sido desestimadas, en la omnipotencia del sueño, en la actividad desinteresada del pensamiento. Tiende a provocar la ruina definitiva de todos los otros mecanismos psíquicos, y a suplantarlos en la solución de los principales problemas de la vida. Han hecho profesión de fe de SURREALISMO ABSOLUTO: Aragon, Baron, Boiffard, Breton, Carrive, Crevel, Delteil, Desnos, Eluard, Gérard, Limbour, Malkine, Morise, Naville, Noll, Péret, Picon, Soupault, Vitrac.

(Extracto del Manifiesto surrealista)
El Manifiesto, publicado en 1924, fue la partida de nacimiento oficial del movimiento surrealista cuyo germen provenía de los escritos de Nerval y Apollinaire, y fue esbozado en Les champs magnétiques. El surrealismo propugnaba un lenguaje libre del freno de la razón y la lógica, quien hablaba era el subconsciente liberado por los sueños, la locura o el uso de estupefacientes, una forma de pensamiento libre que se asemeja al habla de la infancia, tan lleno de fantasía y espontaneidad. Breton y sus correligionarios hicieron explícita la deuda que tenían con los estudios de Freud, especialmente con la interpretación de los sueños. Esta era la marca de agua psiquiátrica en la obra de Breton. "Estoy muy entusiasmado con la psiquiatría" le escribió un joven André a su amigo Theodore Fraenkel cuando este se mostraba muy escéptico con las teorías freudianas, para tal fin André copió a mano páginas enteras de las obras del Dr. Emmanuel Régis para intentar convencer a su amigo. Esta impronta freudiana en la mente de André pasó por alto los verdaderos aportes de Charcot en la histeria y de Pierre Janet en el automatismo psíquico. Más tarde, Babinski crearía otra marca indeleble en el pensamiento de André al refutar el concepto de Charcot respecto a la histeria separando los casos de enfermedad neurológica de los producidos por sugestión, a los que Babinski denominó pitiatismo. Una clara demostración de la admiración que le tenía André a su profesor se encuentra en los párrafos finales del Manifiesto del surrealismo de 1924:

"El material que necesita acumular a su alrededor tampoco me impone respeto: ni sus tubos de vidrio ni mis plumas metálicas [está hablando de los científicos]. En cuanto a su método, no doy más por él que por el mío; he visto actuar al inventor del reflejo cutáneo plantar; manipulaba sin descanso sus sujetos; y lo que practicaba era algo muy distinto de un 
examen: resultaba evidente que no se subordinaba a ningún plan. Aquí y allá hacía una observación, como de lejos, sin dejar su alfiler y sin interrumpir la carrera de su martillo de reflejos. La tarea fútil de tratar los enfermos la delegaba en otros. Estaba totalmente absorbido por esa fiebre sagrada."

Babinski, el inventor del reflejo plantar, el eminente neurólogo evaluando a sus pacientes con tal pasión -la "fiebre sagrada"- y destreza que había convertido el examen neurológico en algo parecido a un automatismo que en apariencia lo convertía en un acto surrealista. Breton y sus secuaces querían liberar al pensamiento de toda lógica y represión para cambiar el orden de las cosas y de la estética:

"Terminemos de una vez: lo maravilloso es siempre bello, cualquier especie de maravilloso es bello, y no hay nada fuera de lo maravilloso que sea bello."

El surrealismo había comenzado oficialmente, tenía una genealogía, tenía padres, tenía definiciones claras y había alborotado el círculo social, político y artístico, primero de Francia, luego Europa, luego América. La vida de Breton entró en una vorágine.

En uno de aquellos días, saliendo de comprar el último libro de Trotsky en la librería L’Humanité se encontró con una joven "pobremente vestida" cuyos ojos, según André, reflejaban una oscura aflicción y a la vez una arrogancia resplandeciente. La joven se llamaba Léona-Camille-Ghislaine Delcourt, se hacía llamar Nadja "porque en ruso es el principio de la palabra esperanza y solo porque es el principio".

Nadja se convertiría en una obra capital en la producción literaria de Breton. Una novela que no fue escrita como novela. Para tal fin el autor eliminó cualquier descripción literaria y en el proemio menciona que "el tono adaptado para el relato copia el de la observación médica, especialmente a la neuropsiquiátrica, que tiende a conservar los datos de todo cuanto examen e interrogatorio pueden revelar sin apurarse por adornar en lo más mínimo el estilo al anotarlo".

En esta novela el narrador comienza preguntándose “QQuién soy?" para luego elucubrar una serie de respuestas, algunas filosóficas, otras artísticas; luego hace la promesa de contar el relato tal como viene, sometido a las normas del azar. El narrador toma el nombre y la persona de Breton incorporando datos biográficos, el Hotel des Grands Hommes, Littérature, los surrealistas, las calles, monumentos y teatros de París por donde solía caminar el mismo Breton. El encuentro con Nadja es singular para el narrador, quien siente de inmediato una atracción emocional, además de sus rasgos físicos emana desenfado y libertad, la misma Nadja se autodenomina "un alma errante". Al finalizar este episodio, el narrador ansía futuros encuentros que ocurrirán primero por azar luego por conveniencia. Si bien la atracción alcanza un cénit, el hechizo inicial comienza a evaporarse.

La narración continúa con evocaciones de los sueños de ambos, lectura recíproca de cartas. $\mathrm{El}$ amor aparece entre ambos pero es furtivo y efímero. El narrador se desencanta de Nadja tan ajena a las convenciones, al sentido común y a las ataduras sociales.

La novela está salpicada con fotografías del París, con sus monumentos, teatros, hoteles y cafés así como de los dibujos de Nadja que representan sus sueños y pensamientos, animales quiméricos y de collages de aspecto onírico. 
Tiempo más tarde el narrador, ya separado de Nadja, se entera que ella esta recluida en el hospital psiquiátrico de Vaucluse, en este punto la novela da un giro y el narrador entabla una dura crítica a los asilos psiquiátricos y al ejercicio de la psiquiatría en general, refiriendo que esa especialidad aún está en pañales.

La lectura de la novela está impregnada por una esencia psiquiátrica, se alude a casos de locura circular, de paranoia, de alucinaciones, semblanzas de psiquiatras de la época e incluso a una obra teatral, Las desequilibradas, acerca de un caso de locura circular y periódica en un internado de señoritas. En 1956 se publicó la versión completa de esta obra en la revista $L e$ surrealisme y se revelaron detalles de su génesis, el actor cómico Palau había solicitado asesoría en la descripción de los casos psiquiátricos y consultó con su amigo, el cirujano Paul Thiery, quien le recomendó a un especialista: el neurólogo Joseph Babinski.

André Breton aludía a la ausencia de frontera entre locura y no-locura, más aun, mencionó que algunos poetas imitan en sus obras síntomas psiquiátricos. Breton no se podía desligar de sus estudios de medicina, en 1928 publicó junto a Louis Aragon un manifiesto por el quincuagésimo aniversario de la histeria y en su Segundo manifiesto de 1930 comienza con la publicación de los Anales médico-psicológicos, Diario de la Alienación Mental y de la Medicina Legal de los Alienados, fechado en 1929, donde el señor Paul Abely hace referencia a la novela Nadja, queera leída por muchos alienados en los manicomios y se hacía referencia a la voluntad del narrador de matar psiquiatras. Abély denomina al surrealismo, aquella "voluntaria incoherencia". A continuación, se devela una discusión de la Sociedad Médico Psicológica que discute los alcances del surrealismo que afirma que la realidad es fea por definición y que el hombre introduce la belleza saliendo de la realidad, como en la frase final de Nadja:

\section{"La belleza será convulsiva o no será."}

Convulsión, relámpago efímero, estremecedor, acaso el persistente recuerdo de aquellos pacientes que André Breton vio en su recorrido como estudiante en hospitales, asilos y campamentos de guerra.

El surrealismo es hijo de varias entrañas, una de ellas la medicina. 